\title{
Red squirrels mitigate costs of territory defence through social plasticity
}

\section{2}

Erin R. Siracusa ${ }^{a^{*}}$, David R. Wilson ${ }^{\mathrm{b}}$, Emily K. Studd ${ }^{\mathrm{c}}$, Stan Boutin ${ }^{\mathrm{d}}$, Murray M. Humphries ${ }^{\mathrm{c}}$, Ben Dantzere,f ${ }^{\mathrm{e}}$, Jeffrey E. Lane ${ }^{\mathrm{g}}$, Andrew G. McAdam ${ }^{\mathrm{a}}$

${ }^{a}$ Department of Integrative Biology, University of Guelph, Guelph, ON, Canada ${ }^{b}$ Department of Psychology, Memorial University of Newfoundland, St. John's, NL, Canada ${ }^{c}$ Department of Natural Resource Sciences, Macdonald Campus, McGill University, Ste-Annede-Bellevue, QC, Canada

${ }^{\mathrm{d}}$ Department of Biological Sciences, University of Alberta, Edmonton, AB, Canada ${ }^{\mathrm{e}}$ Department of Psychology, University of Michigan, Ann Arbor, MI, USA

${ }^{\mathrm{f}}$ Department of Ecology \& Evolutionary Biology, University of Michigan, Ann Arbor, MI, USA ${ }^{\mathrm{g}}$ Department of Biology, University of Saskatchewan, Saskatoon, SK, Canada

*Correspondence: E. R. Siracusa, Department of Integrative Biology, University of Guelph, 50 Stone Road East, Guelph, ON N1G 2W1, Canada E-mail address: erinsiracusa@gmail.com

\section{Abstract}

For territorial species, the ability to be behaviourally plastic in response to changes in their social environment may be beneficial by allowing individuals to mitigate conflict with conspecifics and reduce the costs of territoriality. Here we investigated whether North American red squirrels (Tamiasciurus hudsonicus) were able to minimize costs of territory defence by adjusting behaviour in response to the familiarity of neighbouring conspecifics. Since red squirrels living in familiar neighbourhoods face reduced intrusion risk, we predicted that increasing familiarity among territorial neighbours would allow squirrels to spend less time on territorial defence and more time in the nest. Long-term behavioural data (1995-2004) collected from the same squirrels across several different social environments indicated that red squirrels reduced rates of territorial vocalizations and increased nest use in response to increasing familiarity with neighbours. In contrast, cross-sectional data (2015-2016), which provided observations from each individual in a single social environment, did not provide evidence of this plasticity. Post- 
32 hoc analyses revealed that evidence of social plasticity in this system was primarily due to

33 within-individual changes in behaviour, which we were unable to estimate in the cross-sectional

34 data. Our results demonstrate that red squirrels can reduce the costs of territoriality by

35 appropriately adjusting behaviour in response to changes in their social environment. However,

36 our results also suggest that estimating plasticity by comparing behaviour among individuals (i.e.

37 cross-sectional analyses) may not always be reliable. Our ability to detect these effects may

38 therefore depend on having data with multiple observations from the same individuals across

39 different social environments.

\section{Keywords}

42 behavioural plasticity, behavioural time budgets, dear enemy, familiarity, red squirrel, social competence, social environment, territoriality, vocalizations

\section{Introduction}

Phenotypic plasticity is one way for organisms to adjust their physiology, morphology,

47 and behaviour when the rate of environmental change outpaces the rate of genetic evolutionary

48 change (Piersma \& Drent, 2003). Broadly defined, phenotypic plasticity is the ability of a given

49 genotype to express multiple phenotypes in response to different environmental conditions

50 (Pigliucci, 2001). Although classic studies of phenotypic plasticity have focused on changes in

51 non-reversible traits (e.g. morphology) that are expressed within a single genotype (Hebert \&

52 Grewe, 1985; Lively, 1986; Greene, 1989), traits that are expressed repeatedly over the course of

53 an organism's lifetime (e.g. timing of reproduction) can be subject to reversible within-individual

54 plasticity (Nussey, Wilson, \& Brommer, 2007; Piersma \& Drent, 2003). This 'reversible

55 plasticity' (Gabriel, Luttbeg, Sih, \& Tollrian, 2005), also referred to as 'phenotypic flexibility'

56 (Piersma \& Drent, 2003), or 'responsiveness' (Wolf, Van Doorn, \& Weissing, 2008), is a

57 powerful mechanism for adapting to changing and unpredictable environmental conditions.

58 Behavioural traits, in particular, show capacity for substantial phenotypic lability in response to

59 changing environmental conditions within an organism's lifetime and can facilitate an

60 organism's ability to cope with both predictable and unpredictable variation in the environment

61 (Ghalambor, Angeloni, \& Carroll, 2010).

62 The social environment is arguably one of the most dynamic and variable realms of an 
63 individual's environment, since high levels of unpredictability are inherent when interacting with

64 other agents that can also exhibit plasticity in behaviour. Examples of social plasticity (changes

65 in behaviour in response to changing social conditions; Sih, Chang, \& Wey, 2014;1 Montiglio,

66 Wey, Chang, Fogarty, \& Sih, 2017) are prevalent. For instance, individuals adjust their level of

67 aggression according to the perceived level of threat imposed by neighbours versus strangers

68 (Temeles, 1994). Interacting individuals change their signaling behaviour in response to

69 bystanders ('audience effect'- Doutrelant, McGregor, \& Oliveira, 2001; Pinto, Oates, Grutter, \&

70 Bshary, 2011). Behaviour may also be affected by previous social experiences such as 'winner-

71 loser effects' (Hsu, Earley, \& Wolf, 2006; Rutte, Taborsky, \& Brinkhof, 2006), as well as by

72 'eavesdropping', in which bystanders extract information from interacting individuals (Earley,

73 2010; Mennill, Ratcliffe, \& Boag, 2002; Oliveira, McGregor, \& Latruffe, 1998).

The ability to adjust behaviour in response to social context should allow individuals to avoid costly interactions while appropriately engaging in other social interactions that might

76 enhance fitness (Taborsky \& Oliveira, 2012). This ability to show adaptive adjustments in social 77 behaviour has been termed 'social skill' (Sih \& Bell, 2008) or 'social competence' (Taborsky \&

78 Oliveira, 2012), although few studies have directly demonstrated fitness benefits of social

79 plasticity (Han \& Brooks, 2015; Patricelli, Uy, Walsh, \& Borgia, 2002; Montiglio et al., 2017).

80 Given the substantial number of social interactions that group-living species must navigate, the

81 benefits of social plasticity are expected to be high in such species (Taborsky, Arnold, Junker, \&

82 Tschopp, 2012). However, solitary, territorial species may also benefit from appropriate

83 adjustments in social behaviour, as being socially plastic may allow individuals to mitigate

84 conflict with conspecifics and reduce the costs of territoriality. For example, gladiator frogs

85 (Hypsiboas rosenbergi) adjust the timing of vocalizations in response to changing levels of

86 conspecific competition. By reducing calling rates in response to changing social conditions,

87 individuals can minimize an energetically costly behaviour (Höbel, 2015).

88 Solitary, territorial species, like their social counterparts, face variation in their social

89 environments through their interactions with territorial neighbours. A well-described example of

90 this variation is differences in familiarity with neighbours (Bebbington et al., 2017; Beletsky \&

91 Orians, 1989; Eason \& Hannon, 1994; Grabowska-Zhang, Wilkin, \& Sheldon, 2012). Long-term

92 social relationships with neighbours have been presumed to be advantageous by minimizing

93 renegotiation of territory boundaries and therefore reducing aggression as well as time and 
94 energy spent on territory defence ('dear-enemy effect'; Fisher, 1954). However, most evidence

95 in support of this cooperative phenomenon comes from experimental studies where individuals

96 are exposed to a familiar and unfamiliar stimulus and a behavioural response is recorded

97 (Temeles, 1994). We know less about how behavioural time budgets are affected by long-term

98 social relationships under natural conditions when individuals may have to navigate territorial

99 dynamics with multiple neighbours (but see Bebbington et al., 2017; Eason \& Hannon, 1994).

100 In this study, we used a longitudinal dataset spanning eight years and cross-sectional data

101 from two years to examine whether territorial North American red squirrels (Tamiasciurus

102 hudsonicus, hereafter 'red squirrels') adjust their behaviour in response to their familiarity with

103 their local social environment. Our long-term dataset contained multiple observations of the

104 same individuals across different social environments, while our cross-sectional data represented

105 an intensive snapshot of a large number of individuals at a single point in time (i.e. a single

106 social environment for each individual), allowing us to compare across individuals to assess

107 differences in behaviour. Although behavioural plasticity is fundamentally a within-individual

108 phenomenon, it can be approximated by comparing among individuals in different environments

109 (Legagneux \& Ducatez, 2013; Slabbekoorn \& Peet, 2003). While this among-individual

110 approach is a useful tool (particularly where it is challenging or time-consuming to collect data

111 on many individuals over several environments) it relies on the critical assumption that the

112 among-individual relationship is an accurate representation of within-individual changes in

113 behaviour.

114 Red squirrels are territorial rodents that defend year-round exclusive territories (Smith,

115 1968). In the Yukon, red squirrels cache white spruce cones (Picea glauca) in a larder hoard

116 called a 'midden' at the center of their territory (Fletcher et al., 2010). This food cache is

117 important for overwinter survival (Kemp \& Keith, 1970; LaMontagne et al., 2013) and both

118 sexes heavily defend these resources from conspecifics, primarily through territorial

119 vocalizations called 'rattles' (Smith, 1978). Rattles function to deter intruders (Siracusa,

120 Morandini, et al., 2017b) but are also individually unique (Digweed, Rendall, \& Imbeau, 2012;

121 Wilson et al., 2015). Rattles therefore carry important information about the local social

122 environment, such as the identity or density of neighbouring conspecifics. Squirrels have been

123 shown to use this acoustic information to increase rattling rates and vigilance and decrease nest

124 use in response to increasing local density (Dantzer, Boutin, Humphries, \& McAdam, 2012). 
125 Additionally, familiarity (length of time as neighbours) with territorial neighbours has been

126 shown in this system to have direct effects on territory intrusion risk. Specifically, individuals

127 living in neighbourhoods with higher average familiarity faced reduced intrusion risk (Siracusa,

128 Boutin, et al., 2017a), consistent with the dear enemy phenomenon (Fisher, 1954).

129 Given these previous findings, we predicted that increasing familiarity with territorial

130 neighbours would allow for decreased time spent on territorial defence as evidenced by (1)

131 decreasing rattling rates and (2) reducing time spent vigilant for conspecifics. We also predicted

132 that, as a squirrel's familiarity with its neighbours increased, squirrels would increase the

133 proportion of time spent in nest, as a proxy for time spent on offspring-care or self-maintenance.

134 Changes in behaviour, as predicted above, would allow individuals to minimize aggression and

135 reduce allocation of time and energy to territory defence under social conditions associated with

136 reduced risk of territorial intrusion, and thus would be indicative of social competence in this

137 species.

Methods

140 We studied a natural population of North American red squirrels located in the southwest

141 Yukon near Kluane National Park $\left(61^{\circ} \mathrm{N}, 138^{\circ} \mathrm{W}\right)$ that has been monitored continuously since

1421987 as part of the Kluane Red Squirrel Project (KRSP; McAdam, Boutin, Sykes, \& Humphries,

143 2007). To assess social plasticity in red squirrels, we measured behaviour of individuals on three

144 study grids characterized by open boreal forest where white spruce is the dominant tree species

145 (Krebs et al. 2001).

146 Using the longitudinal dataset, we analyzed long-term focal animal observations

147 (Altmann, 1974) of 41 red squirrels across eight years (between 1995 and 2004), collected on

148 one unmanipulated control grid (Sulphur: SU; 40 ha). We also examined a cross-section of data

149 by analyzing focal observations of 108 squirrels in one year (2016) on two unmanipulated

150 control grids (Kloo: KL and SU; 40 ha each) and one food supplemented grid (Agnes: AG; 45

151 ha; see Dantzer et al., 2012 for a description of the food supplementation experiment). In

152 addition to using focal animal observations, we measured the behaviour of squirrels by deploying

153 accelerometers in 2016 and audio recorders in 2015 and 2016. On average, squirrels rattle once

154 every 8.24 min (Dantzer et al., 2012), which makes capturing fine-scale adjustments in

155 behaviour challenging, even with the intensive use of focal observations. Therefore, our intention 
156 was to use data from audio recorders and accelerometers as additional measures of social

157 plasticity that might better capture fine-scale adjustments in behaviours such as rattling rates and

158 nest use. This research was approved by the University of Guelph Animal Care Committee (AUP

159 number 1807) and is in compliance with the ASAB/ABS Guidelines for the Use of Animals in

160 Research. Details on these approaches are provided below.

\section{Measuring familiarity}

163 In each year, we enumerated all squirrels living on our study areas and monitored

164 individuals from March until August. We used a combination of live-trapping procedures and

165 behavioural observations to track reproduction, identify territory ownership, and determine

166 offspring recruitment from the previous year (see Berteaux \& Boutin, 2000; McAdam et al.,

1672007 for a complete description of core project protocols). All study grids were staked and

168 flagged at $30 \mathrm{~m}$ intervals, which allowed us to record the spatial location of all squirrel territories

169 to the nearest $3 \mathrm{~m}$. In this study system, territory locations were denoted based on the location of

170 an individual's midden, which approximates the center of a squirrel's territory. We did not

171 explicitly map territory boundaries for all individuals.

172 We trapped squirrels using Tomahawk live traps (Tomahawk Live Trap Co., Tomahawk,

173 Wisconsin, USA) baited with all natural peanut butter. If previously tagged, the identities of the

174 squirrels were determined from their unique alphanumeric metal ear tags (Monel \#1; National

175 Band and Tag, Newport, KY, USA), which they received in their natal nest at around 25 days of

176 age. During the first capture of the season, we marked each squirrel by threading coloured wires

177 through each ear tag, which allowed for individual identification of squirrels during behavioural

178 observations. We censused the population twice annually (in mid-May and mid-August) and

179 determined territory ownership through a combination of consistent live-captures of the same

180 individual at the same midden and behavioural observations of territorial 'rattle' vocalizations

181 (Smith 1978).

$182 \quad$ For each territory owner we defined the social neighbourhood to be all conspecifics

183 whose middens were within a $130 \mathrm{~m}$ radius of the owner's midden. One hundred and thirty

184 meters is the furthest distance that red squirrel rattles are known to carry (Smith, 1978) and is

185 similar to the $150 \mathrm{~m}$ distance found by (Dantzer et al., 2012) to be most relevant for local density

186 effects of the social environment. We measured pairwise familiarity between the territory owner 
187 and each neighbour as the number of days that both individuals were within the same acoustic

188 neighbourhood (i.e. occupied their current neighbouring territories). We then averaged pairwise

189 measures of familiarity between the focal individual and each of the neighbours to provide a

190 measure of the average familiarity of each individual with its entire acoustic neighbourhood

191 (Siracusa, Boutin, et al., 2017a).

\section{Focal observations}

194 Red squirrels are an ideal species for behavioural studies because they are diurnal, easy to

195 locate visually or through acoustic cues, and habituate readily to the presence of humans. As part

196 of the KRSP, we have recorded the behaviour of red squirrels through focal sampling of radio-

197 collared individuals (model PD-2C, 4 g, Holohil Systems Ltd., Ontario, Canada) since 1994,

198 although the sampling protocol has varied slightly across this period. For this study, we chose to

199 use a subset of long-term behavioural data where focal observations were collected in a

200 consistent manner by instantaneous sampling at 30-sec intervals for ten continuous minutes

201 (Altmann, 1974) on a single control grid (SU; $N=487$ 10-min sessions over 41 individuals). We

202 excluded any focals where the squirrel was out of sight for more than half the observation

203 session $(N=8)$. These behavioural observations were available for female squirrels in $1995(N=$

204 41), $1996(N=10), 1997(N=25), 1999(N=34), 2001(N=70), 2002(N=110), 2003(N=$

205 120), and $2004(N=77)$ and were recorded by 38 different observers. On average, data were

206 available for two different social environments per individual (range 1-8). We considered any

207 change in average familiarity during the population census to be a change in the social

208 environment. Since the population was censused twice annually (in mid-May and mid-August)

209 individuals could experience up to two different social environments per year.

210 Between 7 May 2016 and 31 August 2016, we used focal animal sampling as described

211 above for seven continuous minutes, rather than ten, to record red squirrel behaviour $(N=10607$

212 min sessions over 108 individuals). In this cross-sectional data we only had observations from

213 each individual in a single social environment. Since rattling is a rare behaviour and is often

214 missed using instantaneous sampling, in 2016 we recorded all occurrences (Altmann, 1974) of

215 rattle vocalizations emitted by the focal squirrel, including those which fell outside the 30 -sec

216 sampling interval (i.e 'critical incidents'). We used all of these data, including critical incidents,

217 to assess how familiarity affected rattling rates in 2016. Four observers collected behavioural 
218 data on both male $(N=76)$ and female $(N=32)$ squirrels across two control grids (KL and SU)

219 and one food-supplemented grid (AG). We monitored each individual for 2-10 days

220 consecutively (barring inclement weather; mean $=4$ days) and collected an average of 10 focals

221 per individual (range: 2-29). In instances where multiple focal observations were collected for

222 the same squirrel in a single day, observations were kept 30 minutes apart at minimum. Because

223 an observer was in regular attendance at these territories we could be confident that there was no

224 turnover in the social environment during the sampling period for any of these individuals.

225 Territory turnovers in this system are accompanied by substantial rattling and chasing and are

226 therefore easy to detect. The two squirrels for which we observed a disturbance in the local

227 social environment during the sampling period were excluded from this analysis.

228 For all focal sampling, we recorded and classified red squirrel behaviours in a similar

229 way to previous studies of squirrel behaviour in this system (Anderson \& Boutin, 2002; Dantzer

230 et al., 2012; Stuart-Smith \& Boutin, 1994). We classified behaviours according to the following

231 categories: vocalizing ("barking" or "rattling"; Smith, 1978), feeding, foraging, traveling,

232 caching food items, interacting with conspecifics, grooming, resting, vigilant, in nest, or out of

233 sight (unknown behaviour). Vigilance could be distinguished from resting by the alert posture of

234 the squirrel; vigilant squirrels typically had their head up and appeared observant, sometimes

235 standing on their hind limbs, while resting squirrels often had their head tucked down or lay

236 stretched out.

Audio recording and acoustic analysis

239 Between 23 June - 25 September 2015 and 8 May - 1 September 2016, we deployed

240 Zoom H2n audio recorders (Zoom Corporation, Tokyo, Japan) to determine rattling rates of

241 squirrels. We attached recorders with windscreens to $1.5 \mathrm{~m}$ stakes and placed a single recorder in

242 the center of each squirrel's midden. Since Zoom H2n recorders are not weatherproof, we placed

243 an umbrella approximately $30 \mathrm{~cm}$ above each audio recorder to protect it from rain and snow.

244 Each morning, we deployed audio recorders between 0500-0600 h (just before squirrels typically

245 became active). We set audio recorders to record in $44.1 \mathrm{kHz} / 16$ bit WAVE format, and recorded

246 in 2-channel surround mode with the stereo width set to $+6 \mathrm{~dB}$ and the mic gain set to 10 . We

247 allowed audio recorders to run for a full 24 hours, but in this study we only use data collected

248 between $0700-1300 \mathrm{~h}$, which is the period during which squirrels are typically most active 
249 between early summer and early autumn (Studd, Boutin, McAdam, \& Humphries, 2016;

250 Williams et al., 2014). We deployed audio recorders for 137 squirrels $(N=109$ males and $N=28$

251 females) and recorded each squirrel for 5 consecutive days on average (range: 1-13 days; $N=$

252714 days or 4284 hours over 137 individuals). Because we collected audio data over 2 years, we

253 had observations from 2-3 different social environments for 28 of these individuals. Due to the

254 large volume of recordings, we detected rattle vocalizations from recordings automatically using

255 Kaleidoscope software (version 4.3.2; Wildlife Acoustics, Inc., Maynard, MA, USA). Detection

256 settings included a frequency range of $2000-13000 \mathrm{~Hz}$, a signal duration of $0.4-15 \mathrm{~s}$, a

257 maximum intersyllable silence of $0.5 \mathrm{~s}$, a fast Fourier transform size of 512 points

258 (corresponding to a frequency resolution of $86 \mathrm{~Hz}$ and a temporal resolution of $6.33 \mathrm{~ms}$ ), and a

259 distance setting of 2 (this value ensures that all detections are retained).

260 The purpose of using audio recorders was to provide a more accurate estimate of

261 individual rattling rates. A challenge, however, is that the recorders also recorded vocalizations

262 from neighbouring squirrels. Neighbours should be farther away from the recorder. Because

263 sound degrades and attenuates predictably with distance, it should be possible to distinguish

264 between the rattles of focal and neighbour squirrels on the basis of rattle acoustic structure. We

265 tested this by conducting hour-long calibrations on 48 focal individuals between 13 September

266 and 14 October 2015. During these calibrations, audio recorders were set up as described above.

267 A single observer standing near the midden kept the territory owner in sight and recorded

268 whether each rattle belonged to the territory owner or a neighbouring individual.

269 We detected rattle vocalizations from the calibration recordings using Kaleidoscope

270 software (same settings as above). Based on a comparison with the observer's notes, the software

271 detected $100 \%$ of the focal squirrel rattles. We then developed a procedure for distinguishing

272 focal squirrel rattles from other types of detections, including neighbour rattles and non-rattles.

273 First, we automatically measured the acoustic structure of every detection using the software

274 package 'Seewave' (version 2.0.5; Sueur, Aubin, \& Simonis, 2008) in R (see details of structural

275 measures below). Second, we used the structural measurements in a discriminant function

276 analysis in SPSS (software, version 24; IBM Corporation, Armonk, New York, USA) to develop

277 a predictive model for assigning detections to groups (i.e., focal rattle, neighbour rattle, non-

278 rattle). We developed the model using detections from half of the 1-hour calibration files

279 (selected at random), and then tested it for accuracy by applying it to the detections from the 
remaining half. The model correctly assigned $80.6 \%$ of the focal rattles to the 'focal rattle' group, meaning we missed $19.4 \%$ of focal rattles (i.e. false negatives). Some non-rattle detections were also assigned to the 'focal rattle' group, but we removed these by reviewing the spectrograms of all detections categorized as 'focal rattles'. After removing non-rattle detections, $16.0 \%$ of the detections remaining in the 'focal rattle' group were false positives, meaning they were actually from the neighbour instead of the focal squirrel. We then applied the predictive model to the main set of audio files, and reviewed all detections labeled as 'focal rattle' in Kaleidoscope to remove the non-rattle detections.

The structural measures included in the discriminant function analysis were: (1) duration, (2) root-mean-square amplitude, (3) pulse rate, (4) duty cycle, and five variables that measured the distribution of energy in the frequency domain, including (5) peak frequency, (6) first energy

291 quartile, (7) skewness, (8) centroid, and (9) and spectral flatness. Duration, root-mean-square

292 amplitude, pulse rate, and duty cycle were measured from a waveform. Pulse rate is the number

293 of pulses in the rattle minus one, divided by the period of time between the beginning of the first 294 pulse and the beginning of the last (as in Wilson et al., 2015). Duty cycle is the proportion of the 295 rattle when a pulse is being produced. For pulse rate and duty cycle, individual pulses were 296 identified using the 'timer' function in seewave (50\% amplitude threshold; 200-point smoothing window with $90 \%$ overlap). The five energy distribution variables were obtained using the 'specprop' function in seewave, and were based on a mean frequency spectrum (512-point fast

299 Fourier transform, hanning window, 0\% overlap). Peak frequency is the frequency of maximum amplitude. First energy quartile is the frequency below which $25 \%$ of the energy is found.

301 Skewness, centroid, and kurtosis describe the shape of the power spectrum (detailed definitions 302 can be found in Sueur et al., 2008).

Accelerometers

Between 4 May and 1 September 2016, we deployed AXY-3 accelerometers

306 (Technosmart Europe srl., Rome, Italy) on 94 squirrels ( $N=66$ males and $N=28$ females). An

307 accelerometer is an instrument that measures the acceleration of the body along three axes:

308 anterior-posterior (surge), lateral (sway), dorso-ventral (heave) and records temperature,

309 allowing for the characterization of different behavioural patterns. Accelerometers were 310 deployed in combination with radio transmitters (model PD-2C, Holohil Systems Ltd., Ontario, 
311 Canada). Total package weight for collars with both accelerometers and radio transmitters

312 (including battery, packaging, and bonding material) was 9.6 g on average. For a 200-250 g red

313 squirrel (Steele, 1998) this collar weight was less than the recommended 5-10\% of the animal's

314 body weight (Wilson, Cole, Nichols, Rudran, \& Foster, 1996). We deployed accelerometers on

31594 individuals for an average of 9 days per individual (range: $4-17 ; N=873$ days over 94

316 individuals) at a sampling rate of $1 \mathrm{~Hz}$. Accelerometers recorded data constantly while deployed,

317 but for this study we only use data between 06:00-21:00 h to estimate time spent in nest during

318 active hours of the day (Williams et al., 2014).

319 Raw accelerometer data were classified into 5 behavioural categories using threshold

320 values of summary statistics according to the decision tree developed for red squirrel

321 accelerometers and temperature data loggers by Studd et al. (in review). Following methods

322 proposed by Collins et al. (2015), the decision tree was created using 83.8 hours of direct

323 behavioural observations on 67 free-ranging squirrels and had an overall accuracy of correctly

324 classifying known behaviours of $94.9 \%$ (Studd et al. in review). Briefly, warm stable

325 temperatures were used to identify when the animal was in the nest with the additional constraint

326 that the individual must not be moving for the majority of each nest bout. Low acceleration

327 values were associated with not moving, moderate acceleration values denoted feeding, and high

328 acceleration corresponded to travelling. Travelling was further categorized as running when the

329 peak acceleration value of the surge axis was above a threshold of $1.15 \mathrm{G}$.

Statistical analyses

332 Given that previous work in this study system (Dantzer et al., 2012) allowed us to make

333 specific predictions about how squirrels should adjust rattling rates, vigilance and nest use in

334 response to their social environment, here we used univariate models to test for the effects of

335 familiarity on each of these behaviours explicitly. For all models we included local density,

336 measured as the number of squirrels per hectare within $130 \mathrm{~m}$, as a continuous predictor, to

337 account for the fact that previous work in the study system has found local density to be an

338 important predictor of behavioural time budgets (Dantzer et al., 2012). We also included age as a

339 fixed effect in all rattling rate models since we expected that the vigor of territory defence might

340 decline with physical deterioration, but we did not have specific predictions as to how age might

341 affect nest use or vigilance. However, it is important to note that since young squirrels are 
342 inherently unfamiliar with their neighbours and familiarity increases with age, age and

343 familiarity were strongly correlated (Pearson's correlation coefficient ranged between 0.42 and

3440.58 for these analyses) although variance inflation factors were low $(<3$; Zuur, Ieno, \& Elphick,

345 2009). Fixed effects and random effects of all models are summarized in Tables 1 and 2,

346 respectively.

$347 \quad$ Focal data

348 To account for the structural differences in our data sets, multiple observations of the

349 same individuals across different social environments (longitudinal data) versus observations

350 from different individuals, each in a single social environment (cross-sectional data), we

351 analyzed the longitudinal $(N=487$ 10-min sessions) and cross-sectional $(N=10607$-min

352 sessions) focal data separately. In the long-term data, there was a single data point where the

353 number of rattles recorded was 25 times greater than the mean. This outlier was likely an error in

354 data entry and was removed (see Figure S1). We analyzed the effects of neighbourhood

355 familiarity on (1) the frequency of territorial vocalizations (rattles), (2) the proportion of time

356 spent vigilant, and (3) the proportion of time spent in nest. We modeled the frequency of

357 territorial vocalizations using a generalized linear mixed-effect model (GLMM) with a bobyqa

358 optimizer and a Poisson error distribution (log-link) where the response variable was the number

359 of rattles emitted during the 10-min focal session. For both the proportion of time spent in nest

360 and the proportion of time spent vigilant, we fitted a Beta-Binomial model to account for

361 overdispersion in the data (Harrison, 2015). Using the 'cbind' function, we defined the response

362 variable as a 2-column matrix composed of the number of observations of the given behaviour

363 (in nest or vigilant) and the number of observations of all other behaviours (not including

364 observations when the squirrel was out of sight). In all models we included average familiarity

365 and local density as continuous predictors, and for the rattling rate models we included age as a

366 continuous fixed effect. We included grid, sex and observer identity as categorical fixed effects

367 for the 2016 focal data (it was not necessary to include grid or sex for the long-term data as all

368 data were collected on females on a single grid). For both datasets, we included a random

369 intercept term for squirrel identity (squirrel ID) to account for repeated observations of the same

370 squirrels. We also included a random effect of year and observer identity for the long-term

371 dataset to account for inter-individual differences in behavioural scoring.

$372 \quad$ Audio recorder data 
To assess the effects of familiarity on rattling rates derived from the audio recorder data,

374 we fitted a GLMM with a Poisson error distribution (log-link). Our response variable was the

375 number of rattles emitted between 0700 - 13:00 h (i.e. number of 'focal rattles', unadjusted for

376 false positive or false negative error rates; $N=714$ days of recordings). We included average

377 familiarity, local density, age, grid, and sex as covariates in the model, as well as a random

378 intercept term for squirrel ID, and an observation-level random effect (OLRE) to account for

379 overdispersion in the model.

\section{$380 \quad$ Accelerometer data}

Using accelerometer data, we assessed the effect of neighbourhood familiarity on the proportion of time spent in nest between 06:00 - 21:00 h using a Beta-Binomial model $(N=873$ days). Our response variable was defined as above, using a two-column matrix that included the number of nest observations and the number of observations of all other behaviours. We included average familiarity, local density, grid, and sex as fixed effects in the model, and included a random effect for squirrel ID and accelerometer collar.

Upon finding evidence of behavioural plasticity in the long-term data but not the cross-

sectional data (see results below), we conducted an exploratory post-hoc analysis in an attempt to understand the inconsistencies in our results. While the longitudinal data provided multiple measures of the same individuals across different social environments, allowing us to estimate within-individual relationships, we could only estimate among-individual relationships in the

394 thus limiting our ability to detect behavioural plasticity in the cross-sectional data, we re-fit our rattling rate and nest use models from the long-term data using a within-subject mean centering approach. Following the methodology of van de Pol \& Wright (2009), we split our familiarity term into an among-individual effect of familiarity (i.e. the mean familiarity score for an individual across all observations) and a within-individual effect of familiarity (i.e. the deviation in each familiarity observation for each individual from their mean score). We applied the same

400 approach to the 2015 and 2016 audio recorder data for which we had observations from 401 individuals across multiple social environments (Table 3).

402 We conducted analyses using R version 3.4.1 (R Core Team, 2017) and fitted all 
404 all analyses, we fitted generalized additive models to confirm that there were no significant non-

405 linearities between our predictor and response variables. We checked for overdispersion by

406 comparing the ratio of the sum of the squared Pearson residuals to the residual degrees of

407 freedom in each model (Zuur et al., 2009) and assessing whether the sum of squared Pearson

408 residuals approximated a Chi-squared distribution with n-p degrees of freedom (Bolker et al.,

409 2009). As stated above, we accounted for overdispersion in Poisson models by including an

410 observation-level random effect (OLRE; Harrison, 2014). For models with binomial data, we

411 accounted for overdispersion using Beta-Binomial models, which have been demonstrated to

412 better cope with overdispersion in binomial data (Harrison, 2015). We fitted all Beta-Binomial

413 models using the package glmmADMB (version 0.8.3.3; Harrison, 2015; Skaug, Fournier,

414 Nielsen, Magnusson, \& Bolker, 2018). We standardized all continuous fixed effects to a mean of

415 zero and unit variance. For the following results we present all means $\pm \mathrm{SE}$, unless otherwise

416 stated, and consider differences statistically significant at $\mathrm{P}<0.05$.

\section{Results}

Among the years in which we analyzed long-term focal data (1995-2004), variation in average neighbourhood familiarity ranged from 0 (corresponding to when a squirrel first established its territory) to 813 days (mean: $229 \pm 9$ days) and variation in local density ranged

422 from 0.57 to 5.84 squirrels/hectare (mean: $1.93 \pm 0.05$ squirrels/hectare). In our 2015 and 2016

423 data, there was a nearly equivalent amount of variation in average neighbourhood familiarity and

424 local density. Neighbourhood familiarity ranged from 0 to 855 days (mean: $296 \pm 5$ days) and

425 local density ranged from 1.13 to 6.03 (mean: $3.34 \pm 0.03$ squirrels/hectare). Below we discuss

426 the effects of familiarity and age on behavioural patterns. Results for other fixed effects in the

427 models can be found in Table 1.

\section{Longitudinal data}

Territorial defence

431 During the long-term focal observations, red squirrels emitted an average of $0.37 \pm 0.04$

432 rattles per 10-min observation session (range: 0-4), which is equivalent to one rattle every 27.06

433 minutes. (Rattling rates were much lower than in the cross-sectional data (see below) due to

434 differences in behavioural sampling protocol. In 2016, all occurrences of rattling were recorded 
435 as 'critical incidents', while in the long-term data rattles were only recorded if they fell on a 30-

436 second sampling interval. When critical incidents of rattling were removed from the 2016 data,

437 rattling rates dropped to one rattle every 40.55 minutes.) Red squirrels in the longitudinal dataset

438 adjusted their behaviour in response to increasing average neighbourhood familiarity by emitting 439 significantly fewer rattles $(\beta=-0.29 \pm 0.12, z=-2.48, P=0.01$; Figure 1$)$. This corresponds to a

440 predicted three-fold decrease in rattling rates: in neighbourhoods with the lowest familiarity,

441 squirrels were predicted to rattle once every 24.76 minutes and in neighbourhoods with the

442 highest familiarity, only once every 79.75 minutes. The effect of age on rattling rates was

443 marginally non-significant $(\beta=-0.20 \pm 0.11, z=-1.85, P=0.06$; Table 1$)$. On average, squirrels

444 spent $6.0 \pm 0.7 \%$ of their time vigilant, but did not show changes in vigilance behaviour in

445 response to changing familiarity with neighbours $(\beta=0.02 \pm 0.13, z=0.15, P=0.88$; Table 1$)$.

$446 \quad$ Nest use

447 Based on the long-term data, red squirrels spent, on average, $31.0 \pm 2.0 \%$ of their time in

448 nest. Red squirrels responded to changing social conditions by increasing nest use in response to

449 increasing familiarity $(\beta=0.26 \pm 0.12, z=2.31, P=0.02$; Figure 1$)$. This is equivalent to a

450 predicted 24\% increase in nest use: squirrels in neighbourhoods with the lowest familiarity were

451 predicted to spend only $19 \%$ of their time in nest compared to $43 \%$ in neighbourhoods with the

452 highest familiarity.

453

Cross-sectional data

Territorial defence

During focal observations in 2016, red squirrels emitted $0.71 \pm 0.03$ rattles per 7 -min observation session (range: 0-6), which equates to approximately one rattle every 9.80 minutes.

458 Data from audio recorders in 2015 and 2016 provided very similar estimates of rattling rates. We 459 captured, on average, $33.96 \pm 0.72$ rattles per 6-hours of recording (range: $3-123$ ), which, after 460 correcting for the error rates in our discriminant function analysis, is equivalent to one rattle 461 every 9.81 minutes. Based on both cross-sectional focal observations and audio recorder data, 462 neither average familiarity of the social neighbourhood (all $|z|<1.25$, all $P>0.21$ ) nor age (all $|z|$ $463<1.87$, all $P \geq 0.06$ ) were significant predictors of rattling rate (Table 1). Focal observations 464 indicated that red squirrels spent $7.0 \% \pm 0.5 \%$ of their time vigilant, on average, but did not 465 adjust vigilance behaviour in response to changing familiarity with neighbours $(\beta=0.05 \pm 0.07$, 
$z=0.69, P=0.49 ;$ Table 1$).$

Nest use

their time in nest. Accelerometer data from 2016 provided similar estimates of average proportion of time spent in nest during daylight hours $(36.0 \% \pm 0.4 \%)$. Both focal observations

471 and accelerometer data indicated that squirrels did not adjust their nest use in response to

472 familiarity with neighbours (all $|z|<1.22$, all $P>0.22$; Table 1).

Exploratory post-hoc analysis

In our post-hoc analyses we found evidence to suggest that effects of familiarity on rattling rates were primarily due to within-individual changes in behaviour rather than amongindividual differences. In the long-term data, increasing familiarity led to a significant decrease in rattling rates within $(\beta=-0.21 \pm 0.08, z=-2.51, P=0.01)$, but not among individuals $(\beta=-$

$4790.18 \pm 0.12, z=-1.50, P=0.13$; Table 3 ). There was a positive within and among-individual 480 effect of familiarity on nest use, but neither of these effects were significant $($ all $|z|<1.69$, all $P>$ 481 0.08; Table 3). Audio recorder data from 2015 and 2016 also a revealed a significant negative 482 within-individual effect $(\beta=-0.03 \pm 0.01, z=-2.55, P=0.01)$, but not among-individual effect 483 of familiarity on rattling rates $(\beta=0.02 \pm 0.05, z=0.34, P=0.74$; Table 3$)$. Results from the 484 audio data should be interpreted with caution as the inclusion of year in the model affected these results (see Table S1). 

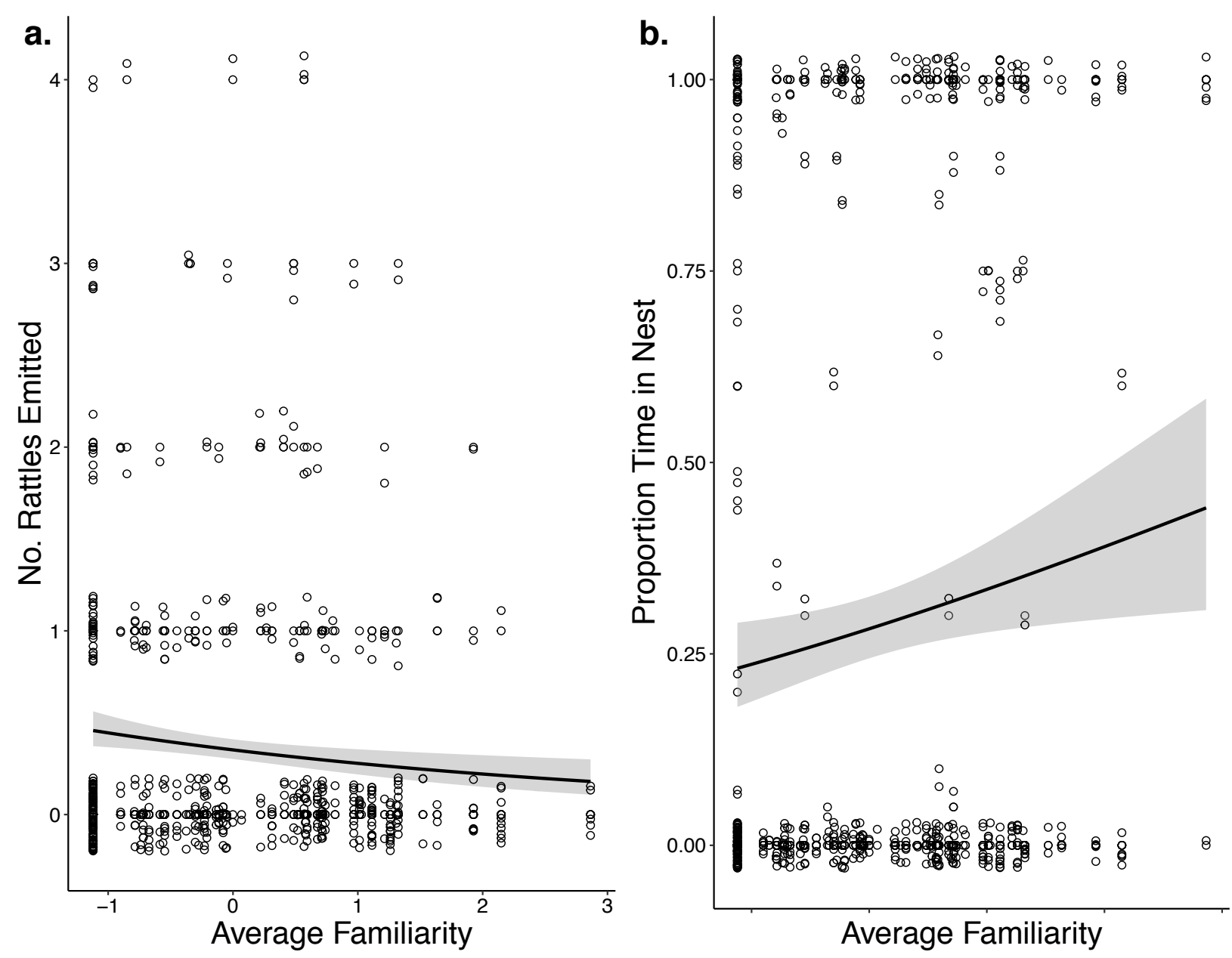

495 Figure 1. Red squirrels adjust a) rattling rate and b) proportion of time spent in nest in response 496 to the average familiarity of their social neighbourhood $(N=487)$. Results are based on 10-min 497 behavioural observations of squirrels between 1995-2004. Values on x-axis are standardized 498 measures of average familiarity. Points indicate raw data with a small amount of jitter introduced 499 to show overlapping points. 
506 Table 1. Fixed effects from all generalized linear mixed-effects (GLMM) and Beta-Binomial

$507(B B)$ models, showing effects of average neighbourhood familiarity, local density, and focal

508 squirrel's age on rattling rate, nest use and vigilance behaviour. Regression coefficients for

509 familiarity, age and density are standardized. Significant effects are indicated in bold.

510

\begin{tabular}{|c|c|c|c|c|c|c|c|}
\hline $\begin{array}{l}\text { Method of data } \\
\text { collection }\end{array}$ & Years & $N$ & Model & Fixed effect & $\begin{array}{l}\text { Parameter +/- } \\
\text { SE }\end{array}$ & $z$ & $P$ \\
\hline \multirow[t]{8}{*}{ Longitudinal focals } & 1995-2004 & 487 & & & & & \\
\hline & & & Rattle rate & Familiarity & $-0.29 \pm 0.12$ & -2.48 & 0.01 \\
\hline & & & $(G L M M)$ & Age & $-0.20 \pm 0.11$ & -1.85 & 0.06 \\
\hline & & & & Density & $-0.17 \pm 0.13$ & -1.38 & 0.17 \\
\hline & & & Vigilance & Familiarity & $0.02 \pm 0.13$ & 0.15 & 0.88 \\
\hline & & & $(B B)$ & Density & $0.05 \pm 0.26$ & 0.19 & 0.85 \\
\hline & & & Nest Use & Familiarity & $0.26 \pm 0.12$ & 2.31 & 0.02 \\
\hline & & & $(B B)$ & Density & $-\mathbf{0 . 3 7} \pm \mathbf{0 . 1 5}$ & -2.53 & 0.01 \\
\hline \multirow[t]{26}{*}{ Cross-sectional focals } & 2016 & 1060 & & & & & \\
\hline & & & Rattle rate & Familiarity & $0.07 \pm 0.07$ & 1.09 & 0.27 \\
\hline & & & $(G L M M)$ & Age & $-0.02 \pm 0.07$ & -0.25 & 0.80 \\
\hline & & & & Density & $-0.12 \pm 0.06$ & -2.01 & 0.04 \\
\hline & & & & Sex-M ${ }^{+}$ & $-0.13 \pm 0.13$ & -1.02 & 0.31 \\
\hline & & & & Grid-KL * & $-0.15 \pm 0.13$ & -1.11 & 0.27 \\
\hline & & & & Grid-SU * & $-0.52 \pm 0.17$ & -3.09 & 0.002 \\
\hline & & & & Obs- JR ${ }^{\dagger}$ & $0.14 \pm 0.25$ & 0.58 & 0.56 \\
\hline & & & & Obs- MT ${ }^{\dagger}$ & $-0.34 \pm 0.09$ & -3.87 & $<0.001$ \\
\hline & & & & Obs- YS ${ }^{\dagger}$ & $-0.47 \pm 0.10$ & -4.92 & $<0.001$ \\
\hline & & & Vigilance & Familiarity & $0.05 \pm 0.07$ & 0.69 & 0.49 \\
\hline & & & & Density & $-0.01 \pm 0.09$ & -0.07 & 0.95 \\
\hline & & & & Sex-M ${ }^{+}$ & $0.26 \pm 0.18$ & 1.48 & 0.14 \\
\hline & & & & Grid-KL * & $-0.42 \pm 0.17$ & -2.48 & 0.01 \\
\hline & & & & Grid-SU * & $-0.36 \pm 0.22$ & -1.63 & 0.10 \\
\hline & & & & Obs- JR ${ }^{\dagger}$ & $0.66 \pm 0.38$ & 1.73 & 0.08 \\
\hline & & & & Obs- MT ${ }^{\dagger}$ & $-0.86 \pm 0.16$ & -5.44 & $<0.001$ \\
\hline & & & & Obs- YS ${ }^{\dagger}$ & $0.44 \pm 0.14$ & 3.24 & 0.001 \\
\hline & & & Nest Use & Familiarity & $-0.11 \pm 0.09$ & -1.21 & 0.23 \\
\hline & & & $(B B)$ & Density & $0.08 \pm 0.10$ & 0.79 & 0.43 \\
\hline & & & & Sex-M ${ }^{+}$ & $0.11 \pm 0.21$ & 0.52 & 0.60 \\
\hline & & & & Grid-KL * & $0.15 \pm 0.22$ & 0.70 & 0.48 \\
\hline & & & & Grid-SU * & $0.50 \pm 0.27$ & 1.85 & 0.06 \\
\hline & & & & Obs- JR ${ }^{\dagger}$ & $-0.59 \pm 0.57$ & -1.02 & 0.31 \\
\hline & & & & Obs- MT ${ }^{\dagger}$ & $0.41 \pm 0.16$ & 2.62 & 0.009 \\
\hline & & & & Obs- YS ${ }^{\dagger}$ & $0.37 \pm 0.16$ & 2.24 & 0.02 \\
\hline \multirow[t]{3}{*}{ Audio recordings } & $2015-2016$ & 714 & & & & & \\
\hline & & & Rattle rate & Familiarity & $-0.05 \pm 0.04$ & -1.24 & 0.21 \\
\hline & & & $(G L M M)$ & Age & $-0.09 \pm 0.05$ & -1.86 & 0.06 \\
\hline
\end{tabular}




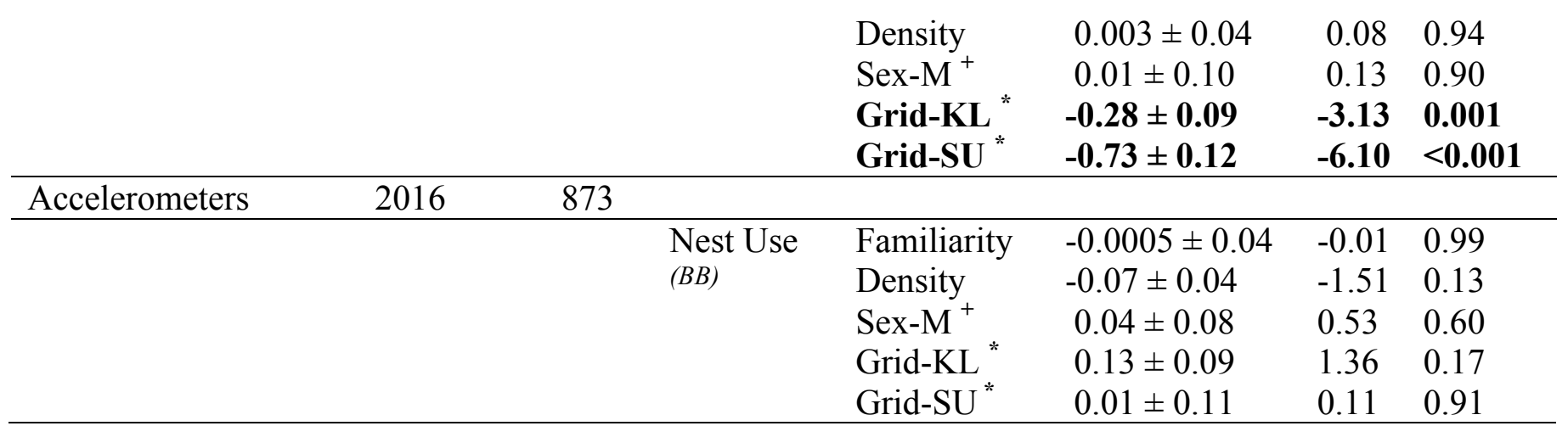

$511+$ Female taken as the reference

$512 *$ AG (food supplemented grid) taken as the reference

$513 \dagger$ Observer ES taken as the reference

514

515

516

517

518

519

520

521

522

523

524

525

526

527

528

529 
530 Table 2. Random effects from all generalized linear mixed-effects (GLMM) and Beta-Binomial $531(B B)$ models. Significance assessed using a log-likelihood ratio test (LRT) with one degree of 532 freedom to compare models with and without the listed random effect. Significant effects are 533 indicated in bold.

534

\begin{tabular}{|c|c|c|c|c|c|c|c|}
\hline $\begin{array}{l}\text { Method of data } \\
\text { collection }\end{array}$ & Years & Model & Random effect & Variance & $\chi^{2}$ & $\mathrm{df}$ & $P$ \\
\hline \multirow{10}{*}{$\begin{array}{l}\text { Longitudinal } \\
\text { focals }\end{array}$} & $1995-2004$ & & & & & & \\
\hline & & Rattle rate & Squirrel ID & 0.09 & 2.19 & 1 & 0.14 \\
\hline & & $(G L M M)$ & Year & $<0.01$ & $<0.01$ & 1 & $>0.999$ \\
\hline & & & Observer & 0.48 & 18.55 & 1 & $<0.001$ \\
\hline & & Vigilance & Squirrel ID & 0.08 & 0.56 & 1 & 0.45 \\
\hline & & & Year & 1.11 & 5.03 & 1 & 0.02 \\
\hline & & & Observer & 0.62 & 10.53 & 1 & 0.001 \\
\hline & & Nest Use & Squirrel ID & $<0.01$ & $<0.01$ & 1 & $>0.999$ \\
\hline & & $(B B)$ & Year & 0.10 & 1.20 & 1 & 0.27 \\
\hline & & & Observer & 0.10 & 1.80 & 1 & 0.18 \\
\hline \multirow{4}{*}{$\begin{array}{l}\text { Cross-sectional } \\
\text { focals }\end{array}$} & 2016 & & & & & & \\
\hline & & $\begin{array}{l}\text { Rattle rate } \\
(G L M M)\end{array}$ & Squirrel ID & 0.14 & 37.53 & 1 & $<0.001$ \\
\hline & & $\begin{array}{l}\text { Vigilance } \\
(B B)\end{array}$ & Squirrel ID & 0.14 & 8.16 & 1 & 0.004 \\
\hline & & $\begin{array}{l}\text { Nest Use } \\
(B B)\end{array}$ & Squirrel ID & 0.32 & 19.20 & 1 & $<0.001$ \\
\hline \multirow[t]{3}{*}{ Audio recordings } & $2015-2016$ & & & & & & \\
\hline & & Rattle rate & Squirrel ID & 0.18 & 422.38 & 1 & $<0.001$ \\
\hline & & $(G L M M)$ & OLRE & 0.06 & 558.11 & 1 & $<0.001$ \\
\hline \multirow[t]{3}{*}{ Accelerometers } & 2016 & & & & & & \\
\hline & & Nest Use & Squirrel ID & 0.10 & 157.58 & 1 & $<0.001$ \\
\hline & & $(B B)$ & AXY No. & $<0.01$ & $<0.01$ & 1 & $>0.999$ \\
\hline
\end{tabular}


541 Table 3. Fixed effects from exploratory post-hoc models including a within-individual

542 (Familiarity $\left.{ }_{W}\right)$ and among-individual (Familiarity ${ }_{A}$ ) effect of familiarity. Regression coefficients

543 for familiarity, age and density are standardized. Significant effects are indicated in bold.

\begin{tabular}{|c|c|c|c|c|c|c|c|}
\hline $\begin{array}{l}\text { Method of data } \\
\text { collection }\end{array}$ & Years & $N$ & Model & Fixed effect & $\begin{array}{l}\text { Parameter } \\
+/- \text { SE }\end{array}$ & $z$ & $P$ \\
\hline \multirow[t]{8}{*}{ Longitudinal focals } & $1995-2004$ & 487 & & & & & \\
\hline & & & Rattle rate & Familiarity $_{W}$ & $-0.21 \pm 0.08$ & -2.51 & 0.01 \\
\hline & & & $(G L M M)$ & Familiarity $_{A}$ & $-0.18 \pm 0.12$ & -1.50 & 0.13 \\
\hline & & & & Age & $-0.22 \pm 0.11$ & -2.02 & 0.04 \\
\hline & & & & Density & $-0.18 \pm 0.13$ & -1.42 & 0.15 \\
\hline & & & Nest Use & Familiarity $_{W}$ & $0.17 \pm 0.10$ & 1.68 & 0.09 \\
\hline & & & $(B B)$ & Familiarity $_{A}$ & $0.19 \pm 0.13$ & 1.53 & 0.13 \\
\hline & & & & Density & $-\mathbf{0 . 3 7} \pm \mathbf{0 . 1 5}$ & -2.50 & 0.01 \\
\hline \multirow[t]{8}{*}{ Audio recordings } & $2015-2016$ & 714 & & & & & \\
\hline & & & Rattle rate & Familiarity $_{W}$ & $-0.03 \pm 0.01$ & -2.55 & 0.01 \\
\hline & & & $(G L M M)$ & Familiarity $_{A}$ & $0.02 \pm 0.05$ & 0.34 & 0.74 \\
\hline & & & & Age & $-0.10 \pm 0.05$ & -2.09 & 0.04 \\
\hline & & & & Density & $-0.02 \pm 0.04$ & -0.56 & 0.58 \\
\hline & & & & Sex-M ${ }^{+}$ & $0.01 \pm 0.10$ & 0.12 & 0.90 \\
\hline & & & & Grid-KL ${ }^{*}$ & $-0.28 \pm 0.09$ & -3.16 & 0.002 \\
\hline & & & & Grid-SU * & $-0.81 \pm 0.12$ & -6.58 & $<0.001$ \\
\hline \multicolumn{8}{|c|}{+ Female taken as the reference } \\
\hline * AG (food supp & ted grid) $t$ & & reference & & & & \\
\hline
\end{tabular}




\section{Discussion}

557 For territorial species, the ability to be responsive to changes in the social environment

558 may convey a fitness advantage by allowing individuals to reduce time and energy investment in

559 costly behaviours (Höbel, 2015; Krobath, Römer, \& Hartbauer, 2017; Ydenberg, Giraldeau, \&

560 Falls, 1988). In this study, we used multiple types of behavioural data, as well as a longitudinal

561 and cross-sectional dataset, to test a single overarching hypothesis: that red squirrels show

562 behavioural plasticity in response to the familiarity of their social neighbourhood. Our results

563 provide evidence that an 'asocial' species, the North American red squirrel, can respond to

564 changes in the composition of its social environment, and that red squirrels do so under natural

565 conditions and in a manner that is consistent with our expectations for adaptive behavioural

566 change in this species.

567 Previous work in this study system has demonstrated that red squirrels face reduced

568 intrusion risk in social neighbourhoods with high average familiarity (Siracusa, Boutin, et al.,

569 2017a). As such, we predicted that red squirrels would show appropriate social plasticity by

570 reducing territorial defence behaviours and increasing time and energy spent on self-maintenance

571 behaviours when familiar with neighbouring conspecifics. Results from behavioural observations

572 across eight years provided support for these predictions, indicating that red squirrels

573 demonstrated social plasticity by reducing rattling rates and increasing the proportion of time

574 spent in nest in social neighbourhoods with high average familiarity (Figure 1). Such changes in

575 behaviour not only minimize the time spent on territory defence but might also reduce associated

576 costs of territoriality. Territorial vocalizations may attract the attention of predators (Abbey-Lee,

577 Kaiser, Mouchet, \& Dingemanse, 2016) and rattles are loud, broadband signals which should be

578 easy to localize (Marler 1955). By reducing rattling rates under less risky social conditions,

579 squirrels may also benefit from reduced predation risk.

580 We did not, however, find effects of neighbourhood familiarity on vigilance behaviour.

581 This could be due to vigilance for conspecifics being easily confounded with vigilance for

582 predators. In contrast, Dantzer et al. (2012) found significant effects of local density on vigilance

583 using behavioural data collected over a similar time frame, indicating that conspecific rather than

584 heterospecific effects on vigilance are detectable in this system. While we included local density

585 as a covariate in all of our models to account for the potential effects of density on behaviour

586 (Dantzer et al., 2012), our goal was not to directly estimate effects of density, and our results 
587 therefore are not a clean representation of density effects. In several cases density was correlated 588 with other variables in the model, such as grid, leading to substantial changes in the parameter 589 estimates for density. As a result, the effects of density on behaviour that we have reported here 590 cannot be compared directly to previous studies of these effects in this population (e.g. Dantzer 591 et al., 2012; Shonfield, Taylor, Boutin, Humphries, \& McAdam, 2012) and we do not discuss the 592 effects of density further.

593 Results from the cross-sectional data in 2015 and 2016 did not corroborate our long-term 594 results showing behavioural responses to familiarity. Findings from the behavioural observations, 595 audio recorders, and accelerometers indicated that when using among-individual relationships to 596 estimate the effects of the social environment on behaviour, there was no effect of familiarity on 597 territorial behaviours (rattling rates, vigilance) or self-maintenance (nest use; Table 1). In light of 598 this inconsistency with the longitudinal data, we conducted an exploratory post-hoc analysis to 599 assess whether using longitudinal data (where we can estimate within-individual changes in 600 behaviour) rather than cross-sectional data (where the analysis is largely among individuals) 601 might account for our different findings. Since behavioural plasticity is functionally a within602 individual phenomenon, using among-individual differences in behaviour to estimate these 603 effects relies on the assumption that the among-individual relationship is an accurate 604 representation of the within-individual relationship. Here we used a within-subject centering 605 approach (van de Pol \& Wright, 2009) and found that the within and among-individual effects 606 were not equivalent. In the long-term data, we found that individuals adjusted rattling rates in 607 response to changes within their own social environment (i.e. a significant within-individual 608 effect) but did not observe significant differences in rattling rates when comparing among 609 individuals (Table 3). Similarly, for the audio recorder data (the only cross-sectional data for 610 which we had observations of individuals across multiple social environments) we found 611 evidence of a significant within-individual, but not among-individual, effect (Table 3). Thus, 612 while we clearly see evidence of plasticity when considering changes in individual behaviour 613 across different social environments, in this study system it appears that we cannot estimate these 614 effects by comparing behaviour among individuals.

615 One potential explanation for this discrepancy is that the among-individual effect is 616 masked by individual variation in plasticity, whereby substantially different individual 'slopes' 617 result in a 'mean slope' of zero (i.e. the absence of a significant population-level response to the 
618 environment; Nussey et al., 2007). We were unable to test this hypothesis as we lacked the

619 statistical power to include a random slope term in our models (Martin, Nussey, Wilson, \& Réale,

620 2011). Furthermore, even if all individuals demonstrate negative reaction norms (i.e. reduced

621 rattling rate in response to increasing familiarity), there are still several reasons we might fail to

622 detect differences among individuals. First, it seems unlikely that squirrels can assess their

623 absolute familiarity, meaning that behavioural adjustments are dependent on the relative social

624 environments individuals experience rather than absolute changes in familiarity. Additionally,

625 variation in individual mean ratting rates (i.e. random intercepts) due to differences in sex, age,

626 personality, stress, among other possibilities, might mask an among-individual effect. These

627 factors, combined with variation in the range of social environments sampled for a given

628 individual, mean that, even when all individuals show negative reaction norms, it is possible to

629 measure a lack of (Figure 2b), or even a positive among-individual effect (Figure 2c). Additional

630 individual data, spanning a range of social environments, is necessary to better understand the

631 patterns leading to within versus among-individual effects in this system.

a. Negative Between-Individual Effect

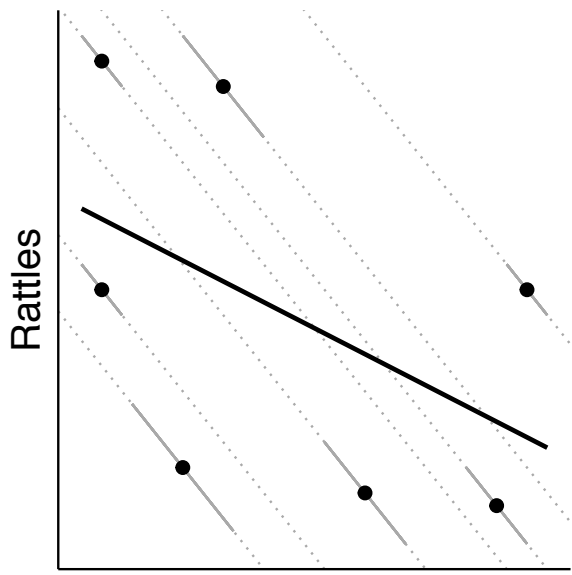

Familiarity

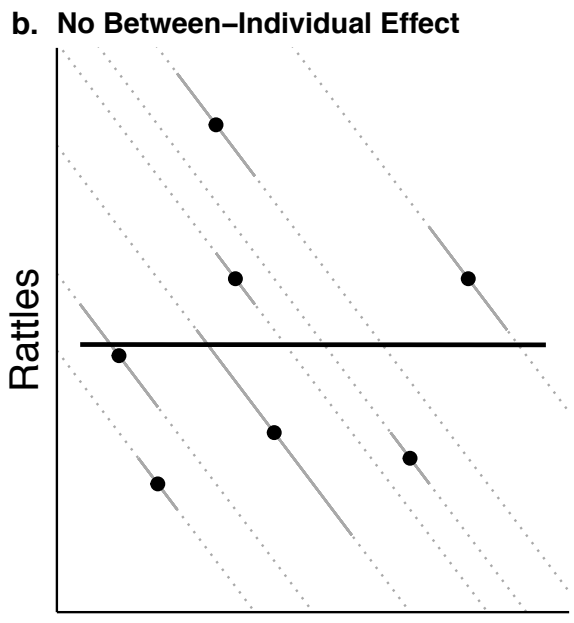

Familiarity

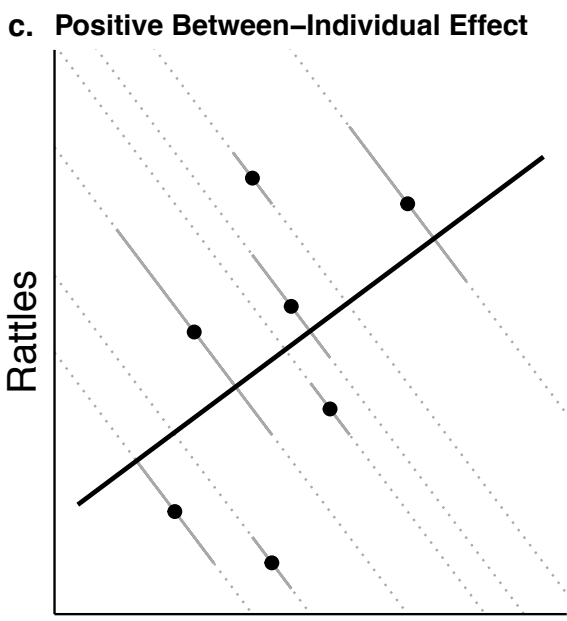

Familiarity

633 Figure 2. Three different scenarios for how variation in mean rattling rate (random intercepts) in

634 combination with variation in data sampling structure might change our ability to detect among-

635 individual effects when individuals have the same slope. We schematically depict the within-

636 individual slopes (solid grey lines) of seven subjects $(j=1$ to $j=7)$. The solid grey lines indicate

637 the range over which each individual was sampled. Dotted lines provide an extension of these

638 slopes to the edge of the figure. The among-subject slope (solid black line) is based on the

639 association between $\bar{x}_{j}$ and $\bar{y}_{j}$ as denoted by the filled black circles. 
Although we have provided an explanation for the differences in our long-term and crosssectional findings, there are a couple reasons why it is important to interpret our results with

642 caution. First, there is potential for changes in rattling rates to be driven by effects of age rather

643 than familiarity if the strength of territory defence declines with physical deterioration. We have

644 done our best to account for this possibility in our analyses, but given that these variables are

645 strongly correlated an experimental approach would prove useful in disentangling these effects

646 as they are difficult to tease apart statistically. Second, it is worth addressing our use of multiple

647 univariate analyses to test a single overarching hypothesis. Previous research in this study system

648 has detected effects of the social environment on vigilance and nest use using a multivariate

649 analysis (Dantzer et al., 2012), allowing us to make specific predictions about how squirrels

650 should adjust patterns of nest use and vigilance in response to neighbourhood familiarity. Given

651 this, we felt that analyzing the effects of familiarity on each of these behaviours individually

652 provided a more elegant test of our hypothesis. However, it is important to be aware that our use

653 of univariate analyses increases our chances of committing a Type I error by attributing variance

654 as unique to a single response variable when it may in fact be shared (Huberty \& Morris, 1989).

655 Despite these limitations, we believe that the results from our study, in particular the data

656 for which we can estimate within-individual changes in behaviour, provide evidence that red

657 squirrels are socially plastic. Furthermore, although we have not directly tested the fitness

658 consequences of social plasticity, red squirrels reduced rattling rates, thereby spending less time

659 on territory defence and potentially minimizing risk of detection by predators, under social

660 conditions where intrusion risk was low (Siracusa, Boutin, et al., 2017a). This suggests that

661 'asocial' species can not only be socially responsive but also socially competent in their

662 behaviour (Taborsky \& Oliveira, 2013; 2012). Familiarity with conspecifics has long been

663 assumed to be beneficial by allowing individuals to minimize energy expended on territory

664 contests and increase time devoted to reproduction and growth (Getty, 1987; Temeles, 1994;

665 Ydenberg et al., 1988). Evidence for reduced aggression toward familiar conspecifics is

666 taxonomically widespread (reviewed in Temeles, 1994). However, these studies have typically

667 been focused on documenting behavioural changes on short timescales through exposure to an

668 experimental stimulus. Our study is one of few to demonstrate that natural variation in

669 neighbourhood familiarity has direct consequences for behavioural time budgets by allowing

670 individuals with familiar neighbours to reduce territory defence and increase time spent in nest. 
671 A handful of previous studies have demonstrated similar patterns in wild populations under

672 natural social conditions. Willow ptarmigan (Lagopus lagopus) males were found to spend

673 significantly more time engaged in territorial border disputes when they had more new

674 neighbours (Eason \& Hannon, 1994). In Seychelles warblers (Acrocephalus sechellensis), living

675 near familiar individuals provided important benefits by reducing immediate energetic costs

676 through fewer physical fights (Bebbington et al., 2017).

677 Additionally, recent research has increasingly noted the importance of group composition

678 in shaping individual behaviour (Farine, Montiglio, \& Spiegel, 2015). For example, nutmeg

679 mannikins (Lonchura punctulata) have been shown to forego consistent individual differences in

680 scrounger-forager tactics when flock composition changes, and to adjust their social strategy

681 according to frequency-dependent pay-offs (Morand-Ferron, Wu, \& Giraldeau, 2011). Water

682 striders (Aquarius remigis) also show plasticity in aggression and activity in response to the

683 presence of hyperaggressive individuals in the group (Sih et al., 2014) or changes in male-male

684 competition (Montiglio et al., 2017). Although territorial species do not act in clearly defined,

685 discrete units, we have demonstrated that red squirrels show similar social plasticity in response

686 to the composition of neighbouring territory holders at the scale of the acoustic social

687 environment (i.e. $130 \mathrm{~m}$ radius). Our results emphasize that the composition of neighbouring

688 conspecifics, in addition to quantity of individuals in the social environment (Dantzer et al.,

689 2012), can shape the behaviour of territorial species.

\section{Conclusion}

692 The advantage of territoriality is contingent on the benefits of resource acquisition

693 outweighing the costs of defending those resources from competitors (Brown, 1964; Schoener,

694 1987). Although the dear-enemy effect has been a well-recognized phenomenon in territorial

695 species for several decades (Temeles, 1994), the relative importance of social interactions for

696 maintaining this cost-benefit ratio under natural conditions has rarely been explored. Here we

697 show that red squirrels adjust their behaviour in response to the familiarity of their social

698 environment and that squirrels living in unfamiliar social neighbourhoods pay a cost in time by

699 increasing rattling rates three-fold and reducing nest use by approximately $25 \%$ in order maintain

700 their territory under conditions of high intrusion risk. Importantly, our results suggest that

701 behavioural plasticity in this species cannot be estimated by comparing differences in behaviour 
702 among-individuals, emphasizing the need to have observations from the same individuals across

703 multiple social environments in order to detect these behavioural patterns.

704 Taken altogether, these results provide evidence that territorial species have the capacity

705 to assess and respond to nuanced changes in their social environment, despite not typically being

706 considered to engage in important social interactions. Social relationships may therefore be more

707 important than previously appreciated for apparently 'asocial' species. Several studies have

708 demonstrated that familiarity with territory neighbours can have fitness benefits, including

709 increased growth rate and survival (Höjesjö, Johnsson, Petersson, \& Järvi, 1998; Seppä, Laurila,

710 Peuhkuri, Piironen, \& Lower, 2001), reduced telomere attrition (Bebbington et al., 2017) and

711 increased reproductive success (Beletsky \& Orians, 1989; Grabowska-Zhang et al., 2012). Given

712 that these long-term social relationships have been demonstrated to affect both intrusion risk

713 (Siracusa, Boutin, et al., 2017a) and behavioural time budgets (this study) in red squirrels, it

714 seems likely that familiarity with territory neighbours could also have important fitness

715 consequences for this species, but this has yet to be explored.

\section{Acknowledgments}

718 We thank all of the field technicians who have contributed to the long-term KRSP

719 database over the years. We are particularly indebted to M.Thorpe, Y.Sun and J. Robertson for

720 their endless hours of squirrel watching and for waking up at unreasonable hours of the morning

721 to deploy audio recorders. We acknowledge that this study was conducted on Champagne and

722 Aishihik First Nations land and thank Agnes MacDonald and her family for long-term access to

723 her trapline. This research was supported by funding from the Natural Sciences and Engineering

724 Research Council of Canada (A.G. McAdam; RGPIN-2015-04707), as well as Grants-in-Aid of

725 research from the American Society of Mammalogists and the Arctic Institute of North America

726 (E.R. Siracusa). This is publication number XX of the Kluane Red Squirrel Project. 


\section{References}

Abbey-Lee, R. N., Kaiser, A., Mouchet, A., \& Dingemanse, N. J. (2016). Immediate and carryover effects of perceived predation risk on communication behavior in wild birds.

Behavioral Ecology, 27(3), 708-716. http://doi.org/10.1093/beheco/arv210

Altmann, J. (1974). Observational study of behavior: sampling methods. Behaviour, 49, 227-267.

Anderson, E., \& Boutin, S. (2002). Edge effects on survival and behaviour of juvenile red squirrels (Tamiasciurus hudsonicus). Canadian Journal of Zoology, 80(6), 1038-1046.

Bates, D., Maechler, M., Bolker, B. M., \& Walker, S. (2015). Fitting linear mixed-effects models using lme4. Journal of Statistical Software, 67(1), 1-48. http://doi.org/doi:10.18637/jss.v067.i01

Bebbington, K., Kingma, S. A., Fairfield, E. A., Dugdale, H. L., Komdeur, J., Spurgin, L. G., \& Richardson, D. S. (2017). Kinship and familiarity mitigate costs of social conflict between Seychelles warbler neighbors. Proceedings of the National Academy of Sciences, 46, 201704350-15. http://doi.org/10.1073/pnas.1704350114

Beletsky, L. D., \& Orians, G. H. (1989). Familiar neighbors enhance breeding success in birds. Proceedings of the National Academy of Sciences, 86(20), 7933-7936. http://doi.org/10.1073/pnas.86.20.7933

Berteaux, D., \& Boutin, S. (2000). Breeding dispersal in female North American red squirrels. Ecology, 81(5), 1311-1326. http://doi.org/10.1890/00129658(2000)081[1311:BDIFNA]2.0.CO;2

Bolker, B. M., Brooks, M. E., Clark, C. J., Geange, S. W., Poulsen, J. R., Stevens, M. H. H., \& White, J.-S. S. (2009). Generalized linear mixed models: a practical guide for ecology and evolution. Trends in Ecology \& Evolution, 24(3), 127-135. http://doi.org/10.1016/j.tree.2008.10.008

Brown, J. (1964). The Evolution of Diversity in Avian Territorial Systems. The Wilson Bulletin, 76(2), 160-169.

Collins, P. M., Green, J. A., Warwick-Evans, V., Dodd, S., Shaw, P. J. A., Arnould, J. P. Y., \& Halsey, L. G. (2015). Interpreting behaviors from accelerometry: a method combining simplicity and objectivity. Ecology and Evolution, 5(20), 4642-4654. http://doi.org/10.1002/ece3.1660

Dantzer, B., Boutin, S., Humphries, M., \& McAdam, A. (2012). Behavioral responses of territorial red squirrels to natural and experimental variation in population density. Behavioral Ecology and Sociobiology, 66(6), 865-878.

Digweed, S. M., Rendall, D., \& Imbeau, T. (2012). Who's your neighbor? Acoustic cues to individual identity in red squirrel Tamiasciurus hudsonicus rattle calls. Current Zoology, 58(5), 758-764. http://doi.org/10.1093/czoolo/58.5.758

Doutrelant, C., McGregor, P., \& Oliveira, R. (2001). The effect of an audience on intrasexual communication in male Siamese fighting fish, Betta splendens. Behavioral Ecology, 12(3), 283-286.

Earley, R. L. (2010). Social eavesdropping and the evolution of conditional cooperation and cheating strategies. Philosophical Transactions of the Royal Society of London B: Biological Sciences, 365(1553), 2675-2686. http://doi.org/10.1098/rstb.2010.0147

Eason, P., \& Hannon, S. J. (1994). New birds on the block: new neighbors increase defensive costs for territorial male willow ptarmigan. Behavioral Ecology and Sociobiology, 34(6), 419-426. http://doi.org/10.1007/BF00167333 
Farine, D. R., Montiglio, P.-O., \& Spiegel, O. (2015). From Individuals to Groups and Back: The Evolutionary Implications of Group Phenotypic Composition. Trends in Ecology \& Evolution, 30(10), 609-621. http://doi.org/10.1016/j.tree.2015.07.005

Fisher, J. (1954). Evolution and bird sociality. In J. Huxley, A. C. Hardy, \& E. B. Ford (Eds.), Evolution as a Process (pp. 71-83). London, U.K.

Fletcher, Q. E., Boutin, S., Lane, J. E., LaMontagne, J. M., McAdam, A. G., Krebs, C. J., \& Humphries, M. M. (2010). The functional response of a hoarding seed predator to mast seeding. Ecology, 91(9), 2673-2683. http://doi.org/10.1890/09-1816.1

Gabriel, W., Luttbeg, B., Sih, A., \& Tollrian, R. (2005). Environmental tolerance, heterogeneity, and the evolution of reversible plastic responses. The American Naturalist, 166(3), 339-353. http://doi.org/10.1086/432558

Getty, T. (1987). Dear enemies and the prisoner's dilemma: why should territorial neighbors form defensive coalitions? Integrative and Comparative Biology, 27(2), 327-336. http://doi.org/10.1093/icb/27.2.327

Ghalambor, C. K., Angeloni, L. M., \& Carroll, S. P. (2010). Behavior as Phenotypic Plasticity. In D. F. Westneat \& C. W. Fox (Eds.), Evolutionary Behavioral Ecology (pp. 90-107). New York, NY.

Grabowska-Zhang, A. M., Wilkin, T. A., \& Sheldon, B. C. (2012). Effects of neighbor familiarity on reproductive success in the great tit (Parus major). Behavioral Ecology, 23(2), 322-333. http://doi.org/10.1093/beheco/arr189

Greene, E. (1989). A Diet-Induced Developmental Polymorphism in a Caterpillar. Science, 243(4891), 643-646. http://doi.org/10.1126/science.243.4891.643

Han, C. S., \& Brooks, R. C. (2015). Same-sex sexual behaviour as a by-product of reproductive strategy under male-male scramble competition. Animal Behaviour, 108(C), 193-197. http://doi.org/10.1016/j.anbehav.2015.07.035

Harrison, X. A. (2014). Using observation-level random effects to model overdispersion in count data in ecology and evolution. PeerJ, 2, e616-19. http://doi.org/10.7717/peerj.616

Harrison, X. A. (2015). A comparison of observation-level random effect and Beta-Binomial models for modelling overdispersion in Binomial data in ecology \& evolution. PeerJ, 3, e1114-17. http://doi.org/10.7717/peerj.1114

Hebert, P. D. N., \& Grewe, P. M. (1985). Chaoborus-induced shifts in the morphology of Daphnia ambigua. Limnology and Oceanography, 30(6), 1291-1297. http://doi.org/10.4319/lo.1985.30.6.1291

Höbel, G. (2015). Socially mediated plasticity of chorusing behavior in the gladiator frog Hypsiboas rosenbergi. Acta Ethologica, 18(2), 145-152. http://doi.org/10.1007/s10211-0140199-z

Höjesjö, J., Johnsson, J. I., Petersson, E., \& Järvi, T. (1998). The importance of being familiar: individual recognition and social behavior in sea trout (Salmo trutta). Behavioral Ecology, 9(5), 445-451. http://doi.org/10.1093/beheco/9.5.445

Hsu, Y., Earley, R. L., \& Wolf, L. L. (2006). Modulation of aggressive behaviour by fighting experience: mechanisms and contest outcomes. Biological Reviews, 81(01), 33-42. http://doi.org/10.1017/S146479310500686X

Huberty, C. J., \& Morris, J. D. (1989). Multivariate analysis versus multiple univariate analyses. Psychological Bulletin, 105(2), 302-308. http://doi.org/10.1037/0033-2909.105.2.302

Kemp, G., \& Keith, L. (1970). Dynamics and regulation of red squirrel (Tamiasciurus hudsonicus) populations. Ecology, 763-779. 
823 Krebs, C. J., Boutin, S. A., \& Boonstra, R. (2001). Ecosystem dynamics of the Boreal Forest:

824

825

826

827

828

829

830

831

832

833

834

835

836

837

838

839

840

841

842

843

844

845

846

847

848

849

850

851

852

853

854

855

856

857

858

859

860

861

862

863

864

865

866

867

868
The Kluane Project. New York, NY: Oxford University Press.

Krobath, I., Römer, H., \& Hartbauer, M. (2017). Plasticity of signaling and mate choice in a trilling species of the Mecopoda complex (Orthoptera: Tettigoniidae). Behavioral Ecology and Sociobiology, 71(11), 164. http://doi.org/10.1007/s00265-017-2381-6

LaMontagne, J. M., Williams, C. T., Donald, J. L., Humphries, M. M., McAdam, A. G., \& Boutin, S. (2013). Linking intraspecific variation in territory size, cone supply, and survival of North American red squirrels. Journal of Mammalogy, 94(5), 1048-1058. http://doi.org/10.1644/12-MAMM-A-245.1

Legagneux, P., \& Ducatez, S. (2013). European birds adjust their flight initiation distance to road speed limits. Biology Letters, 9(5), 20130417-20130417.

http://doi.org/10.1098/rsbl.2013.0417

Lively, C. M. (1986). Predator-Induced Shell Dimorphism in the Acorn Barnacle Chthamalus anisopoma. Evolution, 40(2), 232. http://doi.org/10.2307/2408804

Marler, P. (1955). Characteristics of Some Animal Calls. Nature, 176(4470), 6-8. http://doi.org/10.1038/176006a0

Martin, J. G. A., Nussey, D. H., Wilson, A. J., \& Réale, D. (2011). Measuring individual differences in reaction norms in field and experimental studies: a power analysis of random regression models. Methods in Ecology and Evolution, 2(4), 362-374. http://doi.org/10.1111/j.2041-210X.2010.00084.x

McAdam, A., Boutin, S., Sykes, A., \& Humphries, M. (2007). Life histories of female red squirrels and their contributions to population growth and lifetime fitness. Ecoscience, 14(3), 362-369.

Mennill, D. J., Ratcliffe, L. M., \& Boag, P. T. (2002). Female Eavesdropping on Male Song Contests in Songbirds. Science, 296(5569), 873-873.

http://doi.org/10.1126/science.296.5569.873

Montiglio, P.-O., Wey, T. W., Chang, A. T., Fogarty, S., \& Sih, A. (2017). Correlational selection on personality and social plasticity: morphology and social context determine behavioural effects on mating success. Journal of Animal Ecology, 86(2), 213-226. http://doi.org/10.1111/1365-2656.12610

Morand-Ferron, J., Wu, G.-M., \& Giraldeau, L.-A. (2011). Persistent individual differences in tactic use in a producer-scrounger game are group dependent. Animal Behaviour, 82(4), 811-816. http://doi.org/10.1016/j.anbehav.2011.07.014

Nussey, D. H., Wilson, A. J., \& Brommer, J. E. (2007). The evolutionary ecology of individual phenotypic plasticity in wild populations. Journal of Evolutionary Biology, 20(3), 831-844. $\mathrm{http}: / /$ doi.org/10.1111/j.1420-9101.2007.01300.x

Oliveira, R., McGregor, P., \& Latruffe, C. (1998). Know thine enemy: fighting fish gather information from observing conspecific interactions. Proceedings of the Royal Society of London. Series B: Biological Sciences, 265(1401), 1045-1049.

Patricelli, G. L., Uy, J. A. C., Walsh, G., \& Borgia, G. (2002). Male displays adjusted to female's response. Nature, 415(6869), 279-280. http://doi.org/10.1038/415279a

Piersma, T., \& Drent, J. (2003). Phenotypic flexibility and the evolution of organismal design. Trends in Ecology \& Evolution, 18(5), 228-233.

Pigliucci, M. (2001). Phenotypic Plasticity: Beyond Nature and Nurture. Baltimore, MD: Johns Hopkins University Press.

Pinto, A., Oates, J., Grutter, A., \& Bshary, R. (2011). Cleaner Wrasses Labroides dimidiatus Are 
More Cooperative in the Presence of an Audience. Current Biology.

R Core Team. (2017). R: A language and environment for statistical computing. Vienna, Austria:

R Foundation for Statistical Computing. https://www.R-project.org/.

Rutte, C., Taborsky, M., \& Brinkhof, M. (2006). What sets the odds of winning and losing?

Trends in Ecology \& Evolution, 21(1), 16-21.

Schoener, T. W. (1987). Time Budgets and Territory Size: Some Simultaneous Optimization Models for Energy Maximizers. Integrative and Comparative Biology, 27(2), 259-291. http://doi.org/10.1093/icb/27.2.259

Seppä, T., Laurila, A., Peuhkuri, N., Piironen, J., \& Lower, N. (2001). Early familiarity has fitness consequences for Arctic char (Salvelinus alpinus) juveniles. Canadian Journal of Fisheries and Aquatic Sciences, 58(7), 1380-1385. http://doi.org/10.1139/cjfas-58-7-1380 Shonfield, J., Taylor, R., Boutin, S., Humphries, M., \& McAdam, A. (2012). Territorial defence behaviour in red squirrels is influenced by local density. Behaviour, 149(3-4), 3-4.

Sih, A., \& Bell, A. (2008). Insights for behavioral ecology from behavioral syndromes. Advances in the Study of Behavior, 38, 227-281.

Sih, A., Chang, A. T., \& Wey, T. W. (2014). Effects of behavioural type, social skill and the social environment on male mating success in water striders. Animal Behaviour, 94(C), 9-17. http://doi.org/10.1016/j.anbehav.2014.05.010

Siracusa, E., Boutin, S., Humphries, M. M., Gorrell, J. C., Coltman, D. W., Ben Dantzer, et al. (2017a). Familiarity with neighbours affects intrusion risk in territorial red squirrels. Animal Behaviour, 133, 11-20. http://doi.org/10.1016/j.anbehav.2017.08.024

Siracusa, E., Morandini, M., Boutin, S., Humphries, M. M., Dantzer, B., Lane, J. E., \& McAdam, A. G. (2017b). Red squirrel territorial vocalizations deter intrusions by conspecific rivals. Behaviour, 154(13-15), 1259-1273. http://doi.org/10.1163/1568539X-00003467

Skaug, H., Fournier, D., Nielsen, A., Magnusson, A., \& Bolker, B. M. (2018). Generalized linear mixed models using “AD Model Builder.” Retrieved from http:/glmmadmb.r-forge.rproject.org/

Slabbekoorn, H., \& Peet, M. (2003). Ecology: Birds sing at a higher pitch in urban noise. Nature, 424(6946), 267. http://doi.org/10.1038/424267a

Smith, C. C. (1968). The Adaptive Nature of Social Organization in the Genus of Three Squirrels Tamiasciurus. Ecological Monographs, 38(1), 31-64. http://doi.org/10.2307/1948536

Smith, C. C. (1978). Structure and Function of the Vocalizations of Tree Squirrels (Tamiasciurus). Journal of Mammalogy, 59(4), 793-808. http://doi.org/10.2307/1380144

Steele, M. (1998). Tamiasciurus hudsonicus. Mammalian Species, (586), 1-9.

Stuart-Smith, A., \& Boutin, S. (1994). Costs of escalated territorial defence in red squirrels. Canadian Journal of Zoology, 72(6), 1162-1167.

Studd, E. K., Boutin, S., McAdam, A. G., \& Humphries, M. M. (2016). Nest attendance of lactating red squirrels ( Tamiasciurus hudsonicus): influences of biological and environmental correlates. Journal of Mammalogy, 97(3), 806-814. http://doi.org/10.1093/jmammal/gyw010

Studd EK, Landry-Cuerrier M, Menzies AK, Boutin S, McAdam AG, Dantzer B, Lane JE, Humphries MM. Behavioural classification of low frequency acceleration and temperature data on a free ranging small mammal. Methods in Ecology and Evolution. Manuscript in review.

Sueur, J., Aubin, T., \& Simonis, C. (2008). Seewave, a free modular tool for sound analysis and synthesis. Bioacoustics, 18(2), 213-226. http://doi.org/10.1080/09524622.2008.9753600 
Taborsky, B., \& Oliveira, R. (2013). Social competence vs responsiveness: similar but not same. A reply to Wolf and McNamara. Trends in Ecology \& Evolution.

Taborsky, B., \& Oliveira, R. F. (2012). Social competence: an evolutionary approach. Trends in Ecology \& Evolution, 27(12), 679-688. http://doi.org/10.1016/j.tree.2012.09.003

Taborsky, B., Arnold, C., Junker, J., \& Tschopp, A. (2012). The early social environment affects social competence in a cooperative breeder. Animal Behaviour, 83(4), 1067-1074.

Temeles, E. (1994). The role of neighbours in territorial systems: when are they'dear enemies'? Animal Behaviour, 47(2), 339-350.

van de Pol, M., \& Wright, J. (2009). A simple method for distinguishing within- versus betweensubject effects using mixed models. Animal Behaviour, 77(3), 753-758. http://doi.org/10.1016/j.anbehav.2008.11.006

Williams, C. T., Wilsterman, K., Kelley, A. D., Breton, A. R., Stark, H., Humphries, M. M., et al. (2014). Light loggers reveal weather-driven changes in the daily activity patterns of arboreal and semifossorial rodents. Journal of Mammalogy, 95(6), 1230-1239. http://doi.org/10.1644/14-MAMM-A-062

Wilson, D. E., Cole, F. R., Nichols, J. D., Rudran, R., \& Foster, M. S. (Eds.). (1996). Measuring and monitoring biological diversity: standard methods for mammals. Washington, D.C.: Smithsonian Institution Press.

Wilson, D. R., Goble, A. R., Boutin, S., Humphries, M. M., Coltman, D. W., Gorrell, J. C., et al. (2015). Red squirrels use territorial vocalizations for kin discrimination. Animal Behaviour, 107, 79-85. http://doi.org/10.1016/j.anbehav.2015.06.011

Wolf, M., Van Doorn, G. S., \& Weissing, F. J. (2008). Evolutionary emergence of responsive and unresponsive personalities. Proceedings of the National Academy of Sciences, 105(41), 15825-15830. http://doi.org/10.1073/pnas.0805473105

Ydenberg, R., Giraldeau, L.-A., \& Falls, J. (1988). Neighbours, strangers, and the asymmetric war of attrition. Animal Behaviour, 36(2), 343-347.

Zuur, A. F., Ieno, E. N., \& Elphick, C. S. (2009). A protocol for data exploration to avoid common statistical problems. Methods in Ecology and Evolution, 1(1), 3-14. http://doi.org/10.1111/j.2041-210X.2009.00001.x 